\title{
Quantification of Surface Water-Groundwater Exchanges by GIS Coupled with Experimental Gauging in an Alluvial Environment
}

\author{
Yassyr Draoui ${ }^{1}$, Fouad Lahlou ${ }^{2}$, Jamal Chao ${ }^{3}$ \\ Lhoussaine El Mezouary ${ }^{4}$, Imane Al Mazini ${ }^{5}$, Mohamed Jalal El Hamidi ${ }^{6}$ \\ Laboratory of Energy Engineering and Materials, Faculty of Sciences, Ibn Tofaïl University, Kenitra, Morocco ${ }^{1,2}$ \\ Laboratory of Natural Resources Geosciences (NaResGeo), Faculty of Sciences, Ibn Tofaïl University, Kenitra, Morocco ${ }^{3,5}$ \\ Laboratory of Mathematical analysis, N-CG and applications, Faculty of Sciences, Ibn Tofaïl University, Kenitra, Morocco ${ }^{4}$ \\ Regional Water Centre of Maghreb, LAMERN, Mohammadia School of Engineers, Mohammed V University, Rabat, Morocco
}

\begin{abstract}
Surface water and groundwater are two interrelated components, where the influence of one automatically affects the quantity and quality of the other. These exchange flows are robustly influenced by some mechanisms such as permeability, lithological nature of the soil, landscape, in addition to the difference between the hydrometric height of the river and the piezometric level of groundwater. The study area of Bou Ahmed plain is vulnerable to intensive pumping mainly in the coastal fringe. The increase in water demand, due to demographic development, is accompanied by pressure on groundwater abstraction which causes significant drops of the groundwater level. The main objectives of this study are to develop Geographic Information System database and mathematical models to analyze spatial and temporal hydrogeological characteristics and hydrodynamic functioning of groundwater flow of the Bou Ahmed aquifer. The present work exhibits the characteristics of the river-groundwater exchanges in an alluvial plain. Therefore, we quantified the flows exchanged between a river and its groundwater using GIS tools along with measurements of parameters obtained by the differential gauging, which was carried out in the field, and hydrogeological boreholes data. These quantified flows, moreover, enabled us to eventually estimate the uncertainties related to the use of the GIS method. These results will also be used to support a set of groundwater simulations based on MODFLOW code in the Bou Ahmad aquifer. These models also associated with develop Geographic Information System will help to better plan, manage and control the groundwater resources of this aquifer.
\end{abstract}

Keywords-Surface water and groundwater; river-groundwater exchanges; geographic information system; differential gauging

\section{INTRODUCTION}

Generally, the exchanges between surface water and groundwater are complex. The interactions between these two elements take place by lateral subsurface flow in unsaturated soil, and by infiltration or seepage in the saturated spots. Moreover, Surface Water-Groundwater trade can be seen as an important element affecting the underground hydro-systems balance; it also has a significant impact on the quality of the groundwater by means of the solutes flow (contaminant) associated with the hydric transfer [1].
Numerous researchers have focused on the quantification of surface water-groundwater exchanges by estimating conductance [2]-[9] via the McDonald formula [10]. As a matter of fact, other researches dealing with the connections between a groundwater and a watercourse find that the exchanges are controlled by the same type of mechanism as that of drainage through a saturated semi-permeable layer [11], [12].

In a fluvial plain, both the flow and exchange of groundwater are controlled by a number of parameters. The most notable being: Firstly, the allocation and amplitude of the hydraulic conductivities at the river and the associated fluvial plain residues [13]-[15]; secondly the affiliation among the river's stream stage and the adjacent groundwater gradients. Finally, the geometry and position of the stream channel in conjunction with its flow into the fluvial plain [14]. Conductance is a requisite factor for the quantification of the flows exchanged between a river and the groundwater. In this paper, we first attempt to estimate these flow rates, using the conductance parameter attained by a geographic information system-based method only. Then, the assessment of the flows will be made by taking field measurements (differential gauging). The comparison between the two results allowed guesstimating the uncertainties associated with the use of the GIS method solely.

The Bou Ahmed aquifer is defined by the form of a depression filled from bottom to top by the Pliocene and Quaternary deposits on primary grounds. It is the main supplier of water resources for drinking water of several centers of the area (the cities of Bou Ahmed and Stehat). The increase in water demand, due to demographic development, is accompanied by pressure on groundwater abstraction. This situation causes significant drops of the groundwater level and consequently concern the decision makers responsible for the management and planning of water resources. For this purpose, all collected information (relevant technical reports and experimentations in the terrain of the study area) were processed and led to: (i) Study the hydrogeology characteristics of the Bou Ahmad aquifer; (ii) Exhibits the characteristics of the river-groundwater exchanges (watercourse functioning) in an alluvial plain; (iii) Quantification and direction of the flows 
exchanged as well as the permeability; (iv) Permeability calibration using data from the GIS.

\section{SituATION AND HydROGEOLOGICAL BACKGROUND}

The location of the study area is in the plain of Bou Ahmed, which is one of coastal basins' alluvial plains of the western Mediterranean, that form part of the Rifain domain allocated in northern Morocco [16] (Fig. 1). The bottom of the plain is characterized by a marly substratum of earlier Pliocene age [17], covered by a Quaternary filling formed mostly by fluvial detrital facies with insertions of pebbles and channeled conglomerates [18]. The examined site is crossed by the Tihissasse River; this latter starts at the convergence point of the Elkanar and Bouhya Rivers (Fig. 1) then reaches the plain with an average slope of $0.45 \%$. The regime of these rivers is irregular with a torrential character during rainy periods [16]. From a hydrogeological standpoint, the study area includes groundwater representing the main source of drinking and agricultural water supply. It is characterized by significant thicknesses in the middle of it which decreases towards the peripherals, on top of a transmissivity that varies between $5.2 .10^{-4} \mathrm{~m}^{2} / \mathrm{s}$ and $4.5 .10^{-3} \mathrm{~m}^{2} / \mathrm{s}$ and a storage coefficient of $20 \%$ [18].

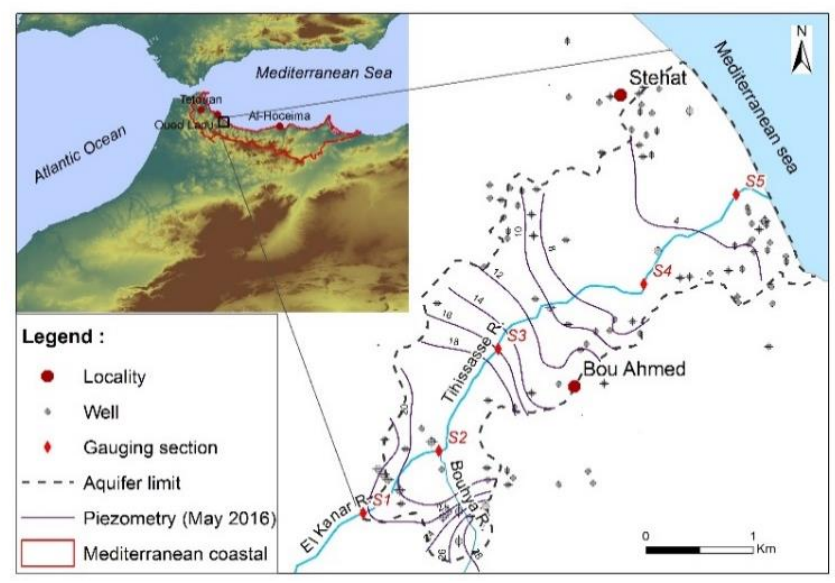

Fig. 1. Geographical Situation and Hydrological / Hydrogeological Backgroud of the Bou Ahmed Aquifer.

\section{Materials AND Methods}

\section{A. Differential Gauging}

The characterization of the groundwater exchange with the river is generally carried out by initially measuring water levels in wells and piezometers within the streambed and the banks of the channel [15], [19]-[23], afterwards, a gauging (Fig. 2) to a number of cross-sections of the watercourse over a short time period [24].

Furthermore, it is principal to acquire in advance some information on the vertical permeability fields of the material constituting the river bed.

In our examination, we implemented a differential gauging campaign (May-2016), exclusively on the Tihissasse River, and the downstream part of the El Kanar River (Fig. 1) since the Bouhya River was almost dried up during this mission. By subdividing the studied area into five sections of measurements
(Fig. 1), we obtained four parts with a river-groundwater contact width of 6 meters for parts 1, 2 and 8 meters for parts 3 and 4.

\section{B. Calculation of Conductance}

To estimate the surface water-groundwater exchanges as well as facilitating the analysis and spatial computation in the GIS, we have transformed the collected data into thematic raster maps whose pixel values symbolize a measured parameter. In this section, the raster calculator was used to generate raster layers of $(2 \times 2 \mathrm{~m})$ dimensions representing thus the value of the difference $\left(\Delta h=h_{a}-h_{r}\right.$ ) between the hydrometric height of the river and the hydraulic head of the groundwater.

Under the GIS, the calculations of the flows exchanged between the river and the groundwater are based on the permeability values of the four sectioned parts $\left(\mathrm{K}_{1}(946)=2.25\right.$ $10^{-4} \mathrm{~m} / \mathrm{s}, \mathrm{K}_{2}(942)=10^{-5} \mathrm{~m} / \mathrm{s}, \mathrm{K}_{3}(943)=3.710^{-5} \mathrm{~m} / \mathrm{s}$ and $\mathrm{K}_{4}$ $\left.(948)=8.210^{-5} \mathrm{~m} / \mathrm{s}\right),[18]$.

For each segment of the river, the vertical exchange rate is generally modelled by the leakage concept based on the [10] law:

$Q\left(m^{3} / d\right)=C *\left(h_{a}-h_{r}\right)$

Where $h_{r}[L]$ is the water level of the river and $h_{a}[L]$ is the water level of groundwater.

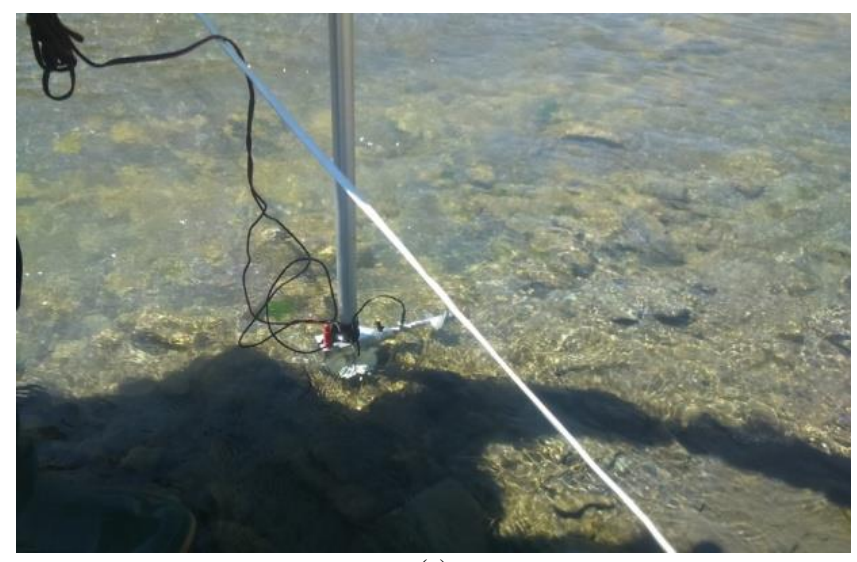

(a)

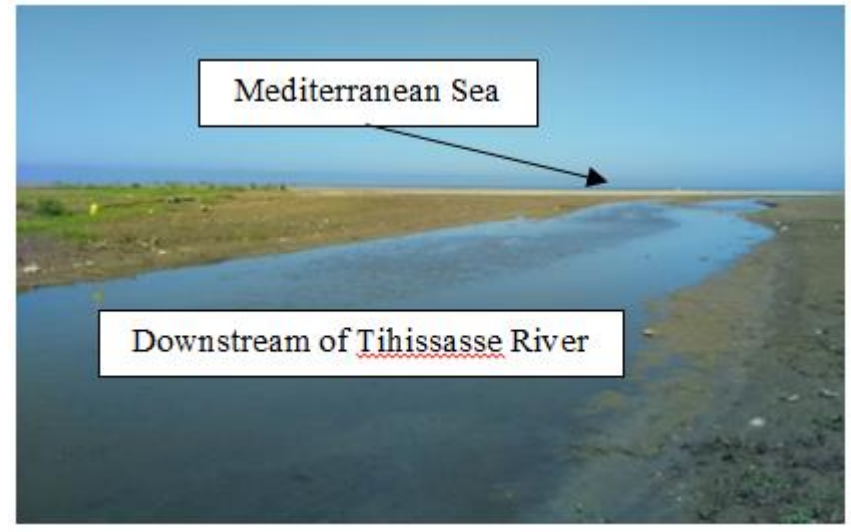

(b)

Fig. 2. (a): Reel with a Horizontal Shaft (b): Downstream Part of the Tihissasse River. 
C represents the conductance in $\left(\mathrm{m}^{2} / \mathrm{d}\right)$ and it's given by the subsequent formula:

$C=\left(K_{z} * S\right) / e$

Where, $K_{z}$ is the vertical permeability $(\mathrm{m} / \mathrm{d}), \mathrm{S}$ indicates the contact surface river- groundwater $\left(\mathrm{m}^{2}\right)$.

Thus, $e$ represents the thicknesses clogged in (m). The following figure illustrates some measurements, along the river, of the parameter of the thickness clogged in the approximate way after the drying of the stream and precisely at the end of August, which varies increasingly from upstream to downstream (Fig. 3).

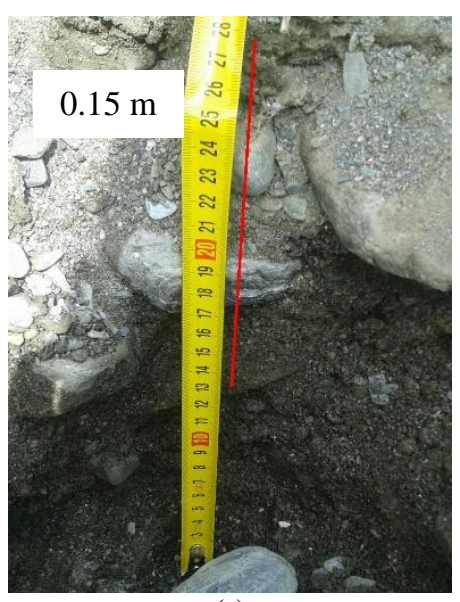

(a)

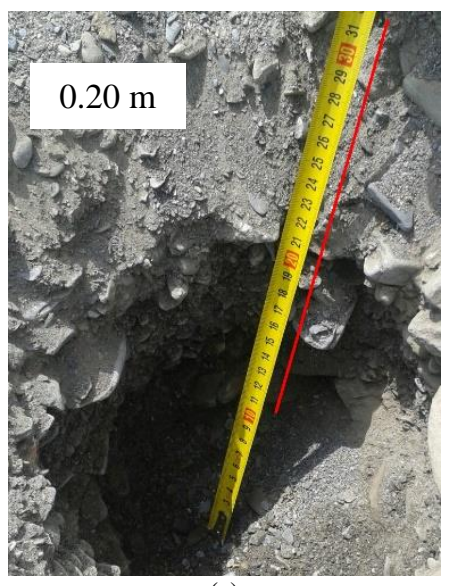

(c)

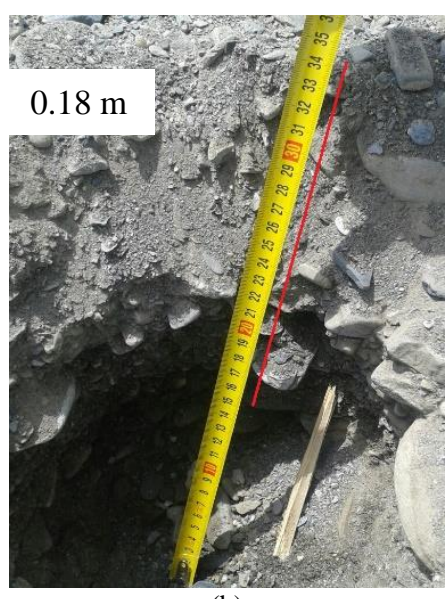

(b)

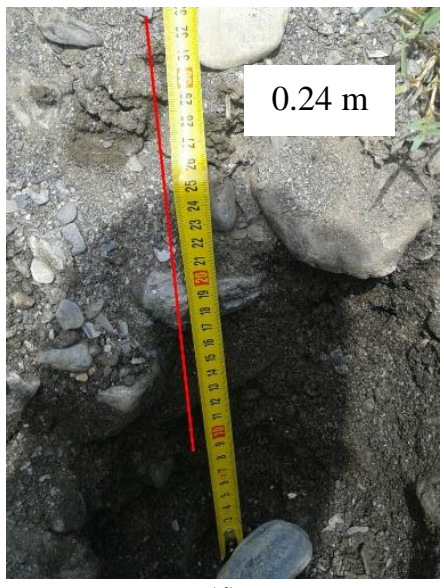

(d)
Fig. 3. (a): River Bed in the upstream of Tihissasse River; (b) and (c): River Bed in the Middle Part; (d): River Bed in the Downstream of the River.

\section{RESULTS}

\section{A. Quantification of the Exchanged Flows}

1) Quantification by gauging: The calculated flow rates from the differential gauge (Table I), for the first two parts, with a total length of approximately $2250 \mathrm{~m}$ are around -3629 $\mathrm{m}^{3} / \mathrm{d}$. Correspondingly, the seized negative values demonstrate that the river supplies the groundwater, which corresponds to a total intake of $-1612 \mathrm{~m}^{3} / \mathrm{d} / \mathrm{km}$. While parts 3 and $4(3000 \mathrm{~m}$ in length) have a flow rate of $15639 \mathrm{~m}^{3} / \mathrm{d}$, this indicates that these sections are provided by the groundwater with a total supply of $5213 \mathrm{~m}^{3} / \mathrm{d} / \mathrm{km}$.

2) Results obtained by GIS method: The raster maps generated from $(\Delta \mathrm{h})$ and the exchange rates $(\mathrm{Q})$ measured for each part of the river (Tab.1) enabled us to approximate the values of the following conductance $\mathrm{Ci}: \mathrm{C}_{1}=2.7488 \mathrm{~m}^{2} / \mathrm{d} ; \mathrm{C}_{2}$ $=0.7595 \mathrm{~m}^{2} / \mathrm{d} ; \mathrm{C}_{3}=0.7625 \mathrm{~m}^{2} / \mathrm{d}$ and $\mathrm{C}_{4}=0.0926 \mathrm{~m}^{2} / \mathrm{d}$, which represent the slopes of the linear regression curves in Fig. 4. This helped us deduce the $e$ parameter by equation (2), which will be used later to calculate the flow rates by the GIS method.

The flow values reaped by the GIS method at four parts demonstrate that the lowest flows are located upstream (2 to -4 $\mathrm{m}^{3} / \mathrm{d} /$ pixel) (parts 1 and 2), whereas the most significant flows are registered downstream of the river with an exchange rate of 63 to $-119 \mathrm{~m}^{3} / \mathrm{d} /$ pixel (parts 3 and 4 ) (Fig. 5).

\section{B. Calibration and Comparison}

To calibrate the permeability values obtained by the GIS method with the experimental ones, we followed a manual calibration methodology; we have systematically modified the permeability values $K_{z}$ in order to minimize the differences between that of the flows given by the GIS method and the ones observed in the field.

During the calibration phase, it was noticed that the flows calculated by GIS (Fig. 5) tend towards the observed flows (Table I) by reducing the $K_{z}$ values (Table II).

TABLE I. AVERAge EXChange Rates RECOUPED by MEASUREMENTS OF THE FIELD FLOWS

\begin{tabular}{|l|l|l|l|l|}
\hline Part & Length $(\mathbf{m})$ & $\begin{array}{l}\text { Average } \\
\text { width }(\mathbf{m})\end{array}$ & $\begin{array}{l}\text { Average slope } \\
\text { (As in \%) }\end{array}$ & $\begin{array}{l}\mathbf{Q}\left(\mathbf{m}^{\mathbf{3}} / \mathbf{d}\right) \\
\text { After } \\
\text { calibration }\end{array}$ \\
\hline Part 1 & 1000 & 6 & 1.1 & -1728 \\
\hline Part 2 & 1250 & 6 & 0.3 & -1901 \\
\hline Part 3 & 1300 & 8 & 0.4 & +6826 \\
\hline Part 4 & 1700 & 8 & 0.4 & +8813 \\
\hline
\end{tabular}




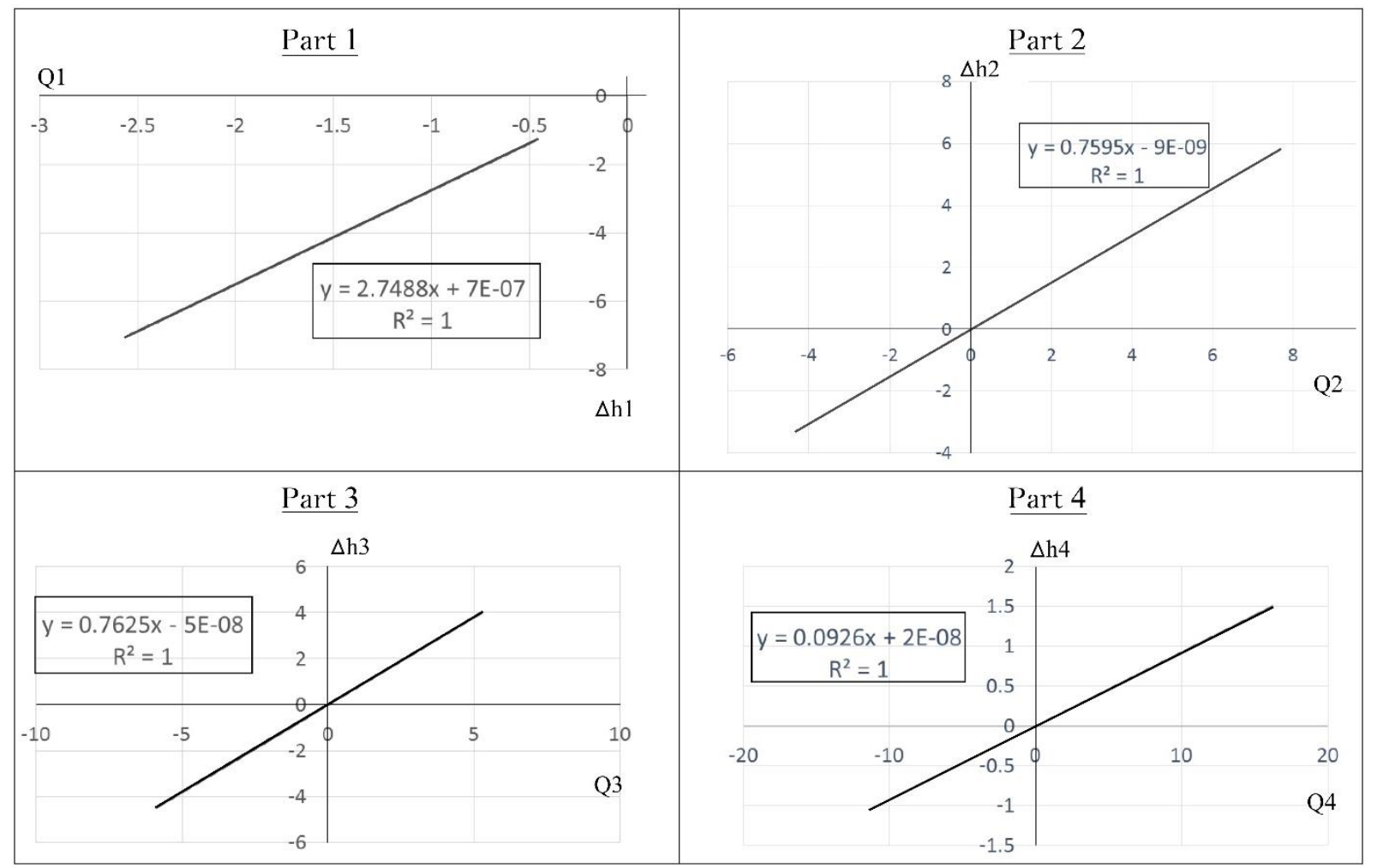

Fig. 4. Illustrations Describing the Flow among the River and Aquifer Q $\left(\mathrm{m}^{3} / \mathrm{s}\right)$ for each Part as a Function of the difference between the River and Groundwater heads $\Delta \mathrm{h}(\mathrm{m})$.

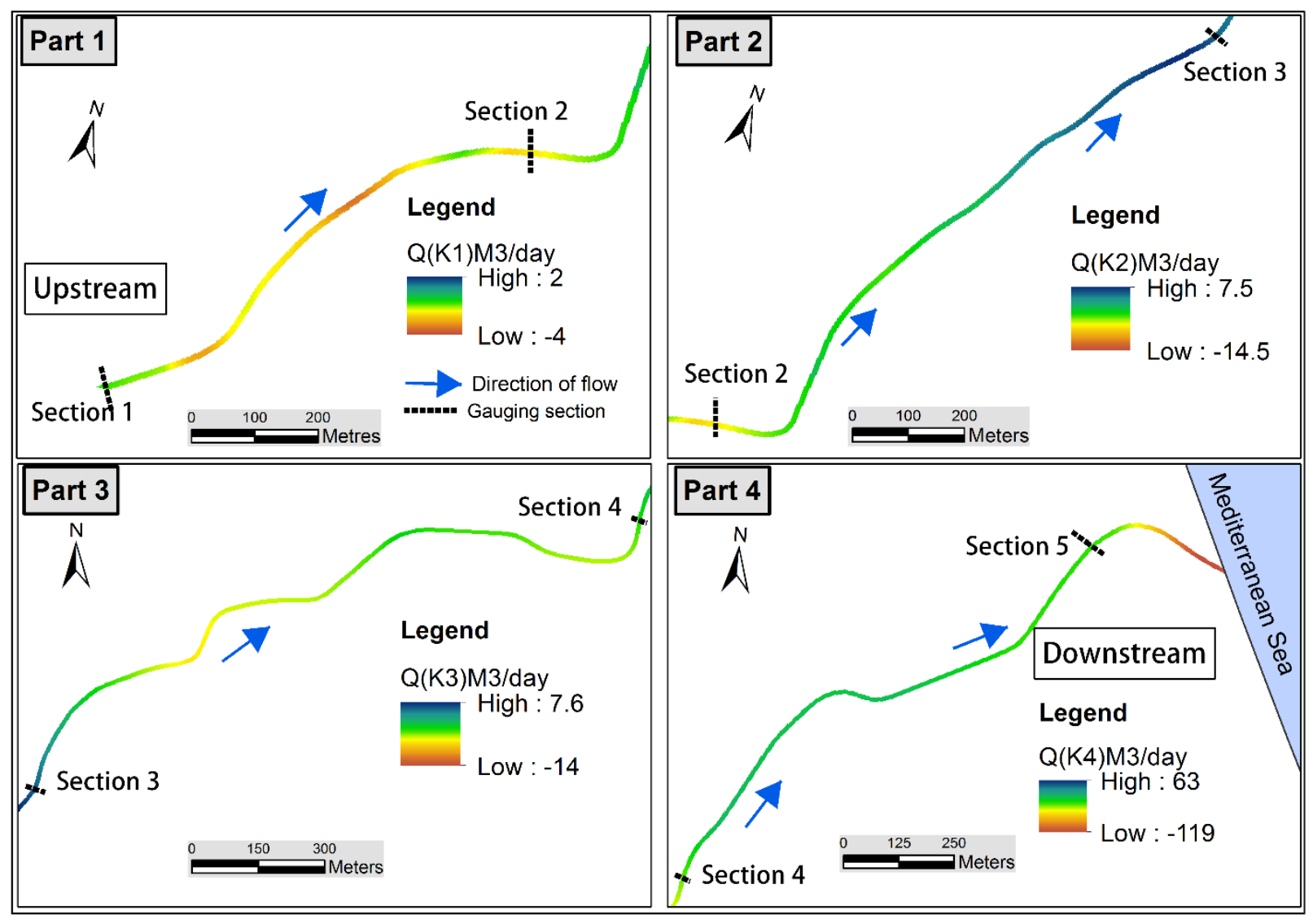

Fig. 5. Maps of Exchanged Flow Values by Parts Obtained from the GIS Method. 
TABLE II. VALUES OF THE PARTS PERMEABILITY BEFORE AND AFTER THE CALIBRATION PHASE OF THE FLOW RATES

\begin{tabular}{|l|l|l|l|}
\hline Part & Length $(\mathbf{m})$ & $\begin{array}{l}\boldsymbol{K}_{\boldsymbol{Z}}(\mathbf{m} / \mathbf{s}) \\
\text { Before calibration }\end{array}$ & $\begin{array}{l}\boldsymbol{K}_{\boldsymbol{Z}}(\mathbf{m} / \mathbf{s}) \\
\text { After Calibration }\end{array}$ \\
\hline Part 1 & 1000 & $2.2510^{-4}$ & $1.010^{-6}$ \\
\hline Part 2 & 1250 & $1.010^{-5}$ & $6.010^{-7}$ \\
\hline Part 3 & 1300 & $3.710^{-5}$ & $2.810^{-6}$ \\
\hline Part 4 & 1700 & $8.210^{-5}$ & $2.310^{-5}$ \\
\hline
\end{tabular}

\section{SYNTHESIS AND DISCUSSION}

Evaluating and interpreting the boreholes data and gauging measurements allowed us to quantify the surface watergroundwater exchanges in the Bou Ahmed plain. Consequently, the exchange principle used is the one proposed [12] which is based on Darcy's law, whose exchange rate is positive when the groundwater feeds the river $(\Delta h>0)$ and negative when the situation is reversed $(\Delta h<0)$.

The attained results illustrate that in the first part; the exchanges are negative (the river feeds the groundwater) (Fig. 6a) with a low flow rate (Table I). This is explained by the existence of mainly sandy silt formations (Fig. 7).

The crossing towards part 2 is characterized by a $\Delta h=0$ (Fig. 6b, Fig. 7), which corresponds to a zero exchange between the surface water and the groundwater. While the remaining of the part is characterized by a $\Delta h<0$ and exchanges that are generally negative (the river feeds the aquifer) (Fig. 6a, Fig. 7). The latter can be explained by a modification in the lithological nature, which changes from sand to pebbles and gravels accompanied by an increase in the thickness of the groundwater from the upstream all the way to the central part of the Tihissasse River (Fig. 7). This thickening is regulated by the roof geometry of the substratum, which is produced by a depression at the level of the borehole (942/4).

It should be noted that at the downstream fraction of part 2, the collected values of the flows by the GIS method are discordant compared to those obtained experimentally, especially in the direction of the exchanges (Fig. 5). This contradiction can be explained by the effect of the measurement sites choice.

For the third and fourth parts, the exchanges are fundamentally positive (the groundwater supplies the river) with a $\Delta h$ varying from -1 to $2 \mathrm{~m}$ (Fig. $6 \mathrm{a}$ and $\mathrm{c}$ ), this is due to the remarkable effect of the substratum surge which favors the overflow of the groundwater.

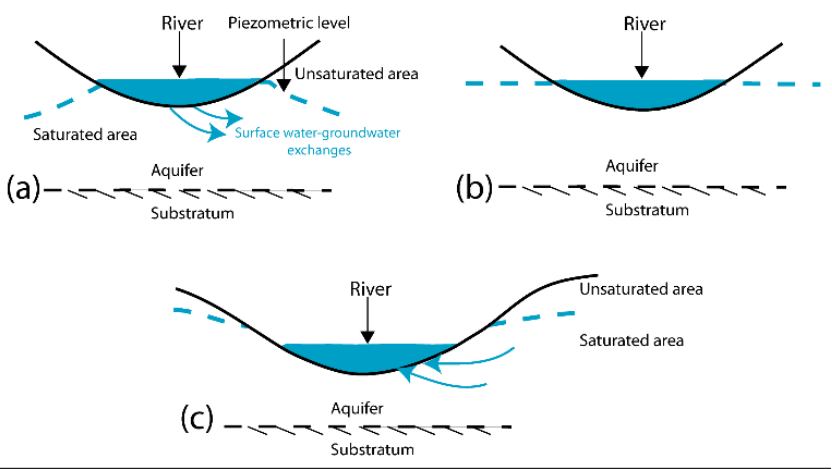

Fig. 6. Possible Situations of Surface Water and Groundwater Exchanges.

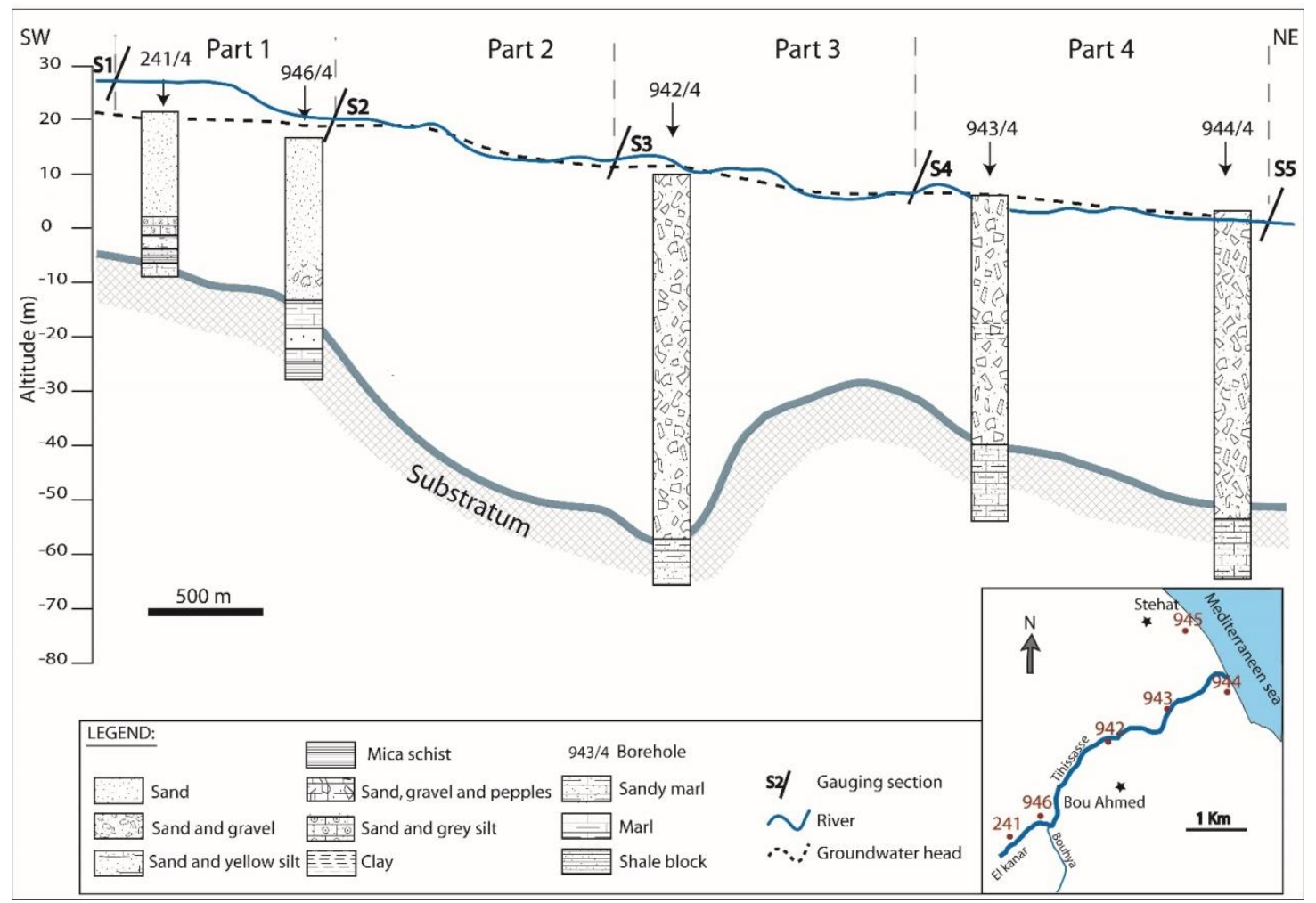

Fig. 7. Synthetic NE-SW Cross-Section along the Watercourse. 


\section{CONCLUSION}

Computer technologies consisting of geographic information systems and numerical modelling are being progressively employed in different geo-resource domains. The characterization method of surface water-groundwater exchanges, based on GIS tools, made it possible to determine the direction of exchange at each point on top of evaluating the exchanged quantity and estimating a relative average balance.

Nevertheless, the satisfactory results supplied by the GIS method, a degree of uncertainty still triumphs, particularly, in case the hydrodynamic parameters are inconsistent. Hence, the requirement to couple the method by calibration based on measures on the ground is recommended.

Concerning the exchanges with the river, a mathematical groundwater flow model can improve the understanding of the functioning of the alluvial aquifers, and as a result to better manage the water resources. The retrieved results have only enhanced the preceding studies, and have given some new interpretations of the hydro-system's behavior of the studied area based on hydrodynamic modelling. Indeed, these results are of great importance to better represent the conceptual model and prepare the input data for groundwater flow model which will be a key decision support system for the decision makers in water resources management, especially for water supply and protection of the aquifer from seawater intrusion.

\section{ACKNOWLEDGMENTS}

The authors would like to thank the Hydraulic Basin Agency of Loukkos-Tetouan (ABHL), who provided us with the necessary database for the fulfilment of this work, and which helped us to realize a campaign of piezometric and gauging measurement.

\section{REFERENCES}

[1] M. Sophocleous, « Interactions between groundwater and surface water: the state of the science », Hydrogeol. J., vol. 10, no 1, p. 52-67, 2002.

[2] I. Cartwright et H. Hofmann, « Using radon to understand parafluvial flows and the changing locations of groundwater inflows in the Avon River, southeast Australia », Hydrol. Earth Syst. Sci., vol. 20, no 9, p. 3581-3600, 2016.

[3] L. El Mezouary et al., « Modélisation numérique de la variation saisonnière de la qualité des eaux souterraines de l'aquifère de Magra, Italie », Houille Blanche, no 2, p. 25-31, 2015.

[4] L. Hu, Z. Xu, et W. Huang, « Development of a river-groundwater interaction model and its application to a catchment in Northwestern China », J. Hydrol., vol. 543, p. 483-500, 2016.

[5] H. J. Morel - Seytoux, C. D. Miller, C. Miracapillo, et S. Mehl, « River Seepage Conductance in Large - Scale Regional Studies », Groundwater, 2016.
[6] X. Sun et al., « Improved simulation of river water and groundwater exchange in an alluvial plain using the SWAT model », Hydrol. Process., vol. 30, no 2, p. 187-202, 2016.

[7] H. J. Morel-Seytoux, C. D. Miller, S. Mehl, et C. Miracapillo, « Achilles' heel of integrated hydrologic models: The stream-aquifer flow exchange, and proposed alternative », J. Hydrol., vol. 564, p. 900-908, 2018.

[8] Y. Cousquer, A. Pryet, N. Flipo, C. Delbart, et A. Dupuy, « Estimating river conductance from prior information to improve surface subsurface model calibration "), Groundwater, vol. 55, no 3, p. 408-418, 2017.

[9] R. Valois, Y. Cousquer, M. Schmutz, A. Pryet, C. Delbart, et A. Dupuy, «Characterizing Stream - Aquifer Exchanges with Self - Potential Measurements », Groundwater, vol. 56, no 3, p. 437-450, 2018.

[10] M. G. McDonald et A. W. Harbaugh, « A modular three-dimensional finite-difference ground-water flow model », 1988.

[11] H. Bouwer, « Theory of seepage from open channels », Adv. Hydrosci., vol. 5, p. 121-172, 1969.

[12] K. Rushton et L. Tomlinson, " Possible mechanisms for leakage between aquifers and rivers », J. Hydrol., vol. 40, no 1-2, p. 49-65, 1979.

[13] T. C. Winter, Ground water and surface water: a single resource, vol. 1139. DIANE Publishing Inc., 1998.

[14] W. W. Woessner, « Stream and fluvial plain ground water interactions: rescaling hydrogeologic thought », Ground Water, vol. 38, no 3, p. 423-429, 2000.

[15] G. J. Wroblicky, M. E. Campana, H. M. Valett, et C. N. Dahm, « Seasonal variation in surface - subsurface water exchange and lateral hyporheic area of two stream - aquifer systems », Water Resour. Res., vol. 34, no 3, p. 317-328, 1998.

[16] J. Thauvin, « Ressources en eau du Maroc, domaine du Rif et du Maroc oriental », Notes Mém. Serv. Géologique Maroc, vol. 231, 1971.

[17] A. El Attar, « Contribution à l'étude hydrogéologique et hydrochimique des aquifères côtiers d'Amsa et de Bou Ahmed (Maroc Nord Occidental) », Univ. Abdelmalek Essaadi, Faculté des Sciences, Tétouan, 2012.

[18] DRHL, « Synthèse hydrogéologique de la plaine de Bou Ahmed, province de Chefchaouen, Maroc ». 1994.

[19] K. Henry et al., " Ground Water Surface Water Exchange in Two Headwater Streams », 1994.

[20] D. R. Lee et J. A. Cherry, « A field exercise on groundwater flow using seepage meters and mini-piezometers », J. Geol. Educ., vol. 27, no 1, p. 6-10, 1979.

[21] E. Modica, « Analytical methods, numerical modeling, and monitoring strategies for evaluating the effects of ground-water withdrawals on unconfined aquifers in the New Jersey Coastal Plain », US Dept. of the Interior, US Geological Survey; Branch of Information Services [distributor], 1998.

[22] F. J. Triska, V. C. Kennedy, R. J. Avanzino, G. W. Zellweger, et K. E. Bencala, « Retention and transport of nutrients in a third - order stream in Northwestern California: Hyporheic processes », Ecology, vol. 70, no 6, p. 1893-1905, 1989.

[23] S. M. Wondzell et F. J. Swanson, « Seasonal and storm dynamics of the hyporheic zone of a 4 th-order mountain stream. I: Hydrologic processes ", J. North Am. Benthol. Soc., vol. 15, no 1, p. 3-19, 1996.

[24] T. J. Buchanan et W. P. Somers, « Discharge measurements at gaging stations », US Govt. Print. Off., 1969. 